\title{
Recent Physical Encounters Affect Chemically Mediated Retreat- Site Selection in a Gecko
}

\author{
Junko Kondo, Sharon J. Downes \& Scott J. Keogh \\ School of Botany and Zoology, Australian National University, Canberra ACT 0200, NSW, Australia
}

\author{
Correspondence \\ Sharon Downes, Australian Cotton Research \\ Institute, Locked Bag 59, Narrabri 2390 NSW. \\ E-mail: sharon.downes@csiro.au \\ Received: May 30, 2006 \\ Initial acceptance: July 10, 2006 \\ Final acceptance: July 11, 2006 \\ (J. Schneider) \\ doi: $10.1111 / \mathrm{j} .1439-0310.2006 .01293 . x$
}

\begin{abstract}
Chemoreception is well documented in a range of animals but the effects of recent behavioural interactions on an animal's response to subsequent chemical information are poorly understood. Using a series of laboratory experiments with a rock-dwelling gecko (Oedura lesueurii), we examined whether latest social experience affects how animals used chemoreception to mediate microhabitat selection. Males of this species defend retreat-sites and the outcomes of physical duels are maintained during second physical contests staged up to $1 \mathrm{wk}$ after first contests. Retreat-site selection experiments showed that past social experience affects the behavioural responses of adult male geckos to chemical cues from conspecific male lizards. When offered a choice between retreatsites labelled with chemicals from an unknown male vs. the opponent from a recent contest, geckos that won their previous fight selected retreat-sites at random. In contrast, under the same conditions, geckos that lost their previous fight significantly preferred retreat-sites scented with an unknown male conspecific over those scented with the winning opponent. During these experiments males that lost their previous fight were significantly more vigilant, and spent greater time near the retreatsite of the unknown male, compared with males that won their previous fight. These results support the notion that recent physical social encounters can affect the way that animals respond to chemical information from potential competitors.
\end{abstract}

\section{Introduction}

Studies of chemoreception test a focal animal's behavioural response towards scent collected from a source individual or substrate (reviewed in Schwenk 1995). Several studies consider how intrinsic factors such as species (Takahashi \& Gassa 1995; Orviel et al. 1997), gender (Cooper \& Perez-Mellado 2002), body condition (Luque-Larena et al. 2001; Lopez et al. 2003), social standing (Schneider et al. 1999; D'Ettorre et al. 2004), and relatedness (Lena et al. 2000) affect the responses of test subjects. For instance, in response to chemical cues from a known snake predator, female lacertid lizards exhibit different behaviours that depend on reproductive state (Downes \& Bauwens 2002).

In species that rely heavily on chemoreception to mediate interactions among animals, individuals may evolve subtle differences in surface chemistry (Alberts et al. 1992; Bull et al. 1999; Whiting 1999; Aragon et al. 2001). The potential advantages and consequences of being able to distinguish among the chemical signals of individuals are numerous. For example, individual-specific chemical cues may be useful in situations where animals direct future mating attempts toward conspecifics that they have or have not encountered previously (Wunderle 1978; Cooper \& Vitt 1985; Ydenberg et al. 1988; Temeles 1994). In the 
context of competition for limited resources, recognition of individual rivals via chemical cues may significantly reduce the costs of contests with predictable outcomes (Olsson 1994). For example, animals may remember the corresponding chemical profiles and agonistic behaviours of previously encountered individuals, and use this information to mediate levels of aggression during subsequent social encounters (Qualls \& Jaeger 1991; Stamps \& Krishnan 1994a; Sakata et al. 2002; Aragon et al. 2003).

A few studies explicitly test how recent physical interactions affect the ways that animals respond to chemical cues. Of particular relevance herein is a study in which encounters were staged between pairs of conspecific mice that were afterwards individually offered a choice between retreat-sites covered with chemical cues from themselves vs. opponents (Hurst et al. 1997). Individuals that lost their recent contest avoided retreat-sites scented with opponents (winners), whereas individuals that won their recent contest randomly selected retreat-sites (Hurst et al. 1997). This experiment demonstrates that recent social experience affects chemically mediated retreat-site selection. However, to make firm predictions about the outcomes of future physical interactions, contestants must be offered retreat-sites scented with opponents vs. unknown conspecifics of the same gender and body condition as opponents.

We used a series of laboratory studies to investigate whether recent social experience affects the ways that lizards respond to chemical information from potential competitors. First, we confirmed that lizards detect and distinguish chemical cues of conspecifics from those of a sympatric heterospecific lizard. We then examined how the outcomes of previous contests affected the subsequent selection of chemically labelled retreat-sites. We hypothesized that winners vs. losers would make different choices between retreat-sites scented with chemical cues of previous opponents vs. unknown opponents. Moreover, we expected that this variation would be in the direction of losers avoiding the cues of previous opponents, and that winners would either randomly select among retreat-sites or prefer those covered with chemical cues of previous opponents.

\section{Methods}

\section{Study System}

Our study animal is the velvet gecko (Oedura lesueuri). This medium-sized lizard is nocturnally active and utilizes loose surface rocks as diurnal retreatsites (Schlesinger \& Shine 1994a). In nature retreatsites of high thermal quality are often in limited supply, while thermal attributes of retreat-sites are the primary determinants of retreat-site selection in this species (Webb \& Shine 2000). Adult males of this species are extremely territorial and engage in physical battles with conspecific males over preferred diurnal retreat-sites (Downes \& Shine 1998a). Field data suggest that geckos show high retreat-site fidelity, rarely move among outcrops, and are active on most nights at least during summer (J. Kondo $\delta$ S. J. Downes, unpubl. data). Therefore, males are likely to engage in consecutive territorial contests for diurnal retreat-sites with the same sample of conspecific competitors.

Velvet geckos detect chemical cues deposited by predatory snakes and can distinguish between chemicals of a predatory and non-predatory species (Downes \& Shine 1998b; Downes \& Adams 2001). This chemosensory ability plays a significant role in the selection of diurnal retreat-sites by geckos (Downes \& Shine 1998b). Anecdotal evidence suggests that geckos can also distinguish among chemical cues deposited by conspecific individuals of different sexes and ages (J. Kondo \& S. J. Downes, unpubl. data). Geckos in their first year of life can distinguish among retreat-sites that are labelled with chemicals from adult females that are mothers vs. non-mothers (S. Downes, unpubl. data).

\section{Animals and their Maintenance}

In October 2002, we captured 60 adult male geckos by hand from Nattai National Park in New South Wales, Australia. The geckos were transported to our laboratory at the Australian National University. Upon arriving all individuals were measured $(\overline{\mathrm{x}} \pm \mathrm{SE}$ snout-vent length $=4.1 \pm 0.7 \mathrm{~cm}$ ) and uniquely marked by injecting a small drop of visible implant elastomer (VIE) under the skin on the ventral side in specific combinations of locations (Kondo $\delta$ Downes 2004). This technique served our need to mark animals temporarily for the study reported herein and permanently for a separate capturemark-recapture study. There are no adverse side effects of this marking method for animals maintained in the laboratory (Kondo \& Downes 2004).

After marking, geckos were housed individually in plastic cages $(12 \times 20 \times 10 \mathrm{~cm})$ maintained in a room at $18^{\circ} \mathrm{C}$. Each cage contained a shelter in the form of two tiles $(10 \times 10 \mathrm{~cm})$ separated vertically to form a crevice. During the day one end of the shelter was 
heated from underneath to $35^{\circ} \mathrm{C}$. The photoperiod was kept constant at L:D of 11:13, which approximates the corresponding cycle in nature. Water and house crickets supplemented with vitamins and calcium were provided ad libitum. After the study duration of 3 months each animal was returned to the rock under which it was captured.

\section{Experimental Procedure}

We tested whether geckos could discriminate chemical cues of conspecifics by gauging their response to three types of chemical cues presented on tiles. (i) We used 1,8 cineole (hereafter referred to as 'cineole') as a pungency control because lizards are exposed to this chemical in nature but it is not related to social interactions with other animals. On the morning of the experiment, we sprayed diluted cineole (1:10, cineole:ethanol) onto tiles and let them dry. (ii) We used adult male Lampropholis delicata as donors of heterospecific chemical cues. This small skink is common throughout eastern Australia (Cogger 2000) and sometimes shares retreat-sites with geckos (J. Kondo, personal observation). We used donor animals that were already in captivity as part of another experiment. (3) We used socially unknown adult male geckos as donors of conspecific cues. Heterospecific and conspecific donor animals deposited chemicals over $3 \mathrm{~d}$ onto tiles that were used as retreat-sites in their home cages. To collect chemical cues from donor animals we made crevices as narrow as possible, so that animals could enter but would deposit chemicals on both the under side of the roof tile and the upper side of the base tile (Schlesinger \& Shine 1994b). All tiles used for experiments had been cleaned using a previously verified protocol (Downes \& Shine 1998b).

All trials were conducted between 19:30 and $22: 30 \mathrm{~h}$ in a room at $18^{\circ} \mathrm{C}$ and we used dim red light to enable observation. We constructed test arenas by turning the roof tile from a retreat-site $(10 \times 20 \mathrm{~cm})$ upside down and abutting it alongside the length of the floor tile. Walls were constructed around the perimeter such that the entire floor of the test arena consisted of the treated tiles. This method was adopted to control for potential variation among test subjects in exposure to treated areas, as may have occurred in arenas that were only partially covered with a treated area. A small opening on one side of the wall provided an entrance into the arena. Each experimental tub was used for only one type of scented treatment. Animals were tested in a pre-set fixed order so that we could test for the effect of this factor in our analyses. Approximately one-third of the geckos were first presented with cineole, onethird were first presented with heterospecific cues and one-third were first presented with conspecific cues. The order of subsequent presentation was: cineole, heterospecific, conspecific.

To commence a trial we placed the test lizard within its home retreat-site next to the entrance of the arena and gently prodded it towards the opening. As soon as the gecko entered the arena, we blocked the opening from the outside. The test animal remained on the tiles for $5 \mathrm{~min}$ undisturbed, during which time we recorded: (i) the number of tongue-flicks directed toward the tiles and (ii) the total amount of time that geckos spent exploring the tile (as opposed to exploring the walls of the arena). These two measures were normally distributed and were used as dependent variables in a MANOVA with 'chemical treatment' and 'order of presentation' as factors. We also performed separate ANOvA's on each measure and used Tukey - Kramer Honestly Significant Difference comparisons tests (hereafter ' $\mathrm{T}-\mathrm{K}$

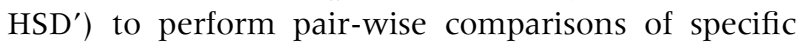
treatments. 'Order of presentation' was always excluded from final models because there was never a significant $(p>0.25)$ main effect or interaction effect concerning this factor.

Our retreat-site selection experiments were designed to test whether social experience affects chemically mediate retreat-site selection. They were conducted in large plastic tubs $(50 \times 100 \times 53 \mathrm{~cm})$ in a room at $18^{\circ} \mathrm{C}$. The bottom of the tub was filled with sand so that geckos could not exploit any gaps between retreat-sites and the floor. The inner sides of the tubs were coated with Fluon to prevent geckos from climbing out. We recorded the behaviour of animals on videotape using surveillance cameras and a video recorder set to extended play. Red lights were positioned above cameras to illuminate the tops of experimental tubs overnight.

To establish the contest outcome experience of lizards, we staged encounters between two geckos (a focal lizard and its opponent). All pairs were evenly matched using body mass and SVL to within $0.3 \mathrm{~g}$ and $2 \mathrm{~mm}$ respectively (Zucker \& Murray 1996). A contest tub contained two unheated retreat-sites, one large $(10 \times 20 \mathrm{~cm})$ and one small $(10 \times 5 \mathrm{~cm})$. The small retreat-site was large enough to house only one adult gecko, and was considerably smaller than the minimum sized retreat-sites occupied by geckos in nature (J. Kondo \& S. J. Downes unpublished data).

Previous studies on adult male velvet geckos demonstrate that individually housed lizards signifi- 
cantly prefer larger retreat-sites rather than smaller retreat-sites (Schlesinger \& Shine 1994b), and that when two lizards are housed together the aggressively superior individual excludes the aggressively inferior individual from preferred retreat-sites through physical interaction (Schlesinger $\&$ Shine 1994a; Downes \& Shine 1998a). These physical interactions include geckos being (1) forced to abandon a secured retreat-site by a conspecific, (2) prevented (usually by chasing) from entering a retreat-site by a conspecific, (3) directly attacked (usually bitten and wrestled by the tail) by a conspecific, and (4) pursued by conspecifics (see Downes 8 Shine 1998a for more details on the frequencies of these interactions). Therefore, we assumed that during our experiments the dominant and subordinate individual in a pair would occupy the larger and smaller retreat-site respectively, and that this end point would be determined through a physical contest between geckos.

We simulated an artificial dusk beginning at 19:30 h. The contests began at 20:00 h when the contestants were placed in the centre of the experimental tub. By this time, the body temperatures of all geckos were at the ambient temperature of $18^{\circ} \mathrm{C}$. They were left undisturbed overnight and returned to their individual home cages the next morning. From the videotapes, we recorded the retreat-site occupied by each individual upon simulating an artificial dawn.

A previous study (Schlesinger \& Shine 1994b) and pilot tests (matching 20 pairs of male geckos under continuous observation) showed that the geckos could be left together safely in our experimental arenas over night. The arenas were large and contained shelters for each gecko. We did not quantify the frequencies of physical interactions between contestants during the pilot trial or experiment but we continuously observed interactions among animals during the first hour of encounters, after which time the level of aggressive encounters was significantly reduced. We planned to terminate trials if there had been severe aggression. No injuries were sustained by animals used in our experiments.

Two days after the experimental encounters, we conducted a retreat-site selection experiment. Focal individuals were offered a choice between two unheated retreat-sites $(10 \times 20 \mathrm{~cm})$, one used by individuals they had fought previously (referred to as 'opponents'), and one used by a male conspecific that they had not encountered before (referred to as 'unknown'). The scent of donor lizards was collected in the same manner as described above for the scent detection experiment. Unknown animals and focal animals were evenly matched using body mass and SVL to within $0.3 \mathrm{~g}$ and $2 \mathrm{~mm}$ respectively. Shortly before $18: 30 \mathrm{~h}$, we translocated the scented retreatsites from the home cages of donor lizards into experimental tubs. By the time the experiment began, the temperatures of the retreat-sites and the geckos were at the ambient temperature of $18^{\circ} \mathrm{C}$. The two retreat-sites treated with different scents were located on opposite sides of the tub. We simulated an artificial dusk beginning at 19:30 h. The experiments began at 20:00 $\mathrm{h}$ when focal animals were placed in the centre of the tubs, and geckos were left undisturbed overnight.

From the videotapes, we recorded the retreat-site occupied by each individual upon simulating an artificial dawn. A goodness-of-fit test was used to examine the interaction between the previous contest outcome of focal animals and the frequency of selecting the scented retreat-site of opponents vs. unknown males. We noted the number of times a gecko entered both retreat-sites and the number of times a gecko entered the opponent's retreat-site. These measures were normally distributed and were used as dependent variables in MANOVA with previous contest outcome of focal animals as the factor. We recorded the amount of time that geckos were not hidden within a retreat-site (time spent active), active and not stationary (time spent mobile), and in the opponent's half of the experimental tub. These measures were normally distributed and were used as dependent variables in a MANOVA with previous contest outcome of focal animals as the factor. We also used the same model to perform ANOva separately for each measure.

\section{Results}

\section{Discrimination of Conspecific Chemical Cues}

The type of chemical treatment presented significantly influenced the behaviour of geckos (MANOva: $\mathrm{df}=2,69, \mathrm{~F}=7.8, \mathrm{p}<0.001)$. Geckos exhibited a higher number of tongue-flicks on tiles covered with scent from male conspecifics compared with tiles covered with scent from male heterospecifics or cineole $(\overline{\mathrm{x}} \pm \mathrm{SE}$ number of tongue-flicks: cineole $=$ $10.3 \pm 1.5$, heterospecific $=14.3 \pm 2.1, \quad$ conspecific $=18.6 \pm 3.0 ; \quad$ ANOVA, $\quad \mathrm{df}=2,69, \quad \mathrm{~F}=3.9, \quad \mathrm{p}=$ 0.023; T-K HSD, $p<0.049$ for conspecific vs. heterospecific and conspecific vs. cineole). Geckos also spent considerably more time investigating the tiles during trials with conspecific scent compared with trials with heterospecific scent or cineole scent $[\bar{x} \pm \mathrm{SE}$ time exploring tiles $(\mathrm{min}):$ cineole $=$ 
$2.9 \pm 0.3$, heterospecific $=3.4 \pm 0.3$, conspecific $=$ $4.0 \pm 0.2 ;$ ANOVA, $\mathrm{df}=2,69, \mathrm{~F}=5.1, \mathrm{p}=0.008 ; \mathrm{T}-\mathrm{K}$ HSD, $\mathrm{p}<0.048$ for conspecific vs. heterospecific and conspecific vs. cineole]. Thus, male geckos can detect chemical cues of conspecific males and distinguish them from heterospecific and control cues.

\section{Does Social Experience Affect Chemically Mediated Retreat-Site Selection?}

During the first hour of the contest, we observed interactions that involved displacement from retreatsites, prevention from entering retreat-sites, attacks and chases. Aggressive encounters were frequent but typically lasted no longer than a few minutes, and subordinate individuals escaped from conspecifics either by seeking shelter in a sub-optimal retreatsite, or fleeing to the opposite end of the enclosure.

All of the initial overnight contests resulted in both geckos in a pair selecting retreat-sites. Of the 30 contest trials conducted, the designated focal individual occupied the large retreat on 17 occasions, and occupied the small retreat on 13 occasions. Hereafter, these males are referred to as 'winners' and 'losers' respectively. During the retreat-site selection experiment, focal individuals always selected one of the retreat-sites at the end of the night.

Geckos that lost their previous contest chose diurnal retreat-sites covered with the scent of unknown male conspecifics significantly more often than those covered with the scent of known males (number of trials: unknown male $=10$, known male $=3$; Binomial test: $\left.\mathrm{df}=1, \chi^{2}=3.8, \mathrm{p}=0.05\right)$. In contrast, geckos that won their previous territorial contest randomly selected retreat-sites covered with the scent of unknown vs. known males (number of trials: unknown male $=7$, known male $=10$; Binomial test: $\mathrm{df}=1, \chi^{2}=0.5, \mathrm{p}=0.50$ ).

There was no significant variation among winning and losing geckos in the tendency to enter retreatsites covered with scent of either opponents or unknown males (MANOvA on 'number of entries to either retreat-site' and 'number of entries to opponent's retreat-site': $\mathrm{df}=2,27, \quad F=2.1, \quad \mathrm{p}=0.137$; Table 1). However, the expression of several aspects of exploratory behaviour differed significantly among geckos that lost their previous contest vs. won their previous contest (MANOVA: $\mathrm{df}=3,26, \mathrm{~F}=3.4, \mathrm{p}=$ 0.032; Table 1). Geckos that lost their previous contest spent significantly less time in the half of the tub containing retreat-sites scented with opponents than did geckos that won their previous contest (ANOva: $\mathrm{df}=1,28, \mathrm{~F}=7.6, \mathrm{p}=0.010 ;$ Table $\mathrm{l}$ ).
Table 1: Expression of the five behaviours measured during the retreat-site selection experiment

\begin{tabular}{lcr}
\hline & \multicolumn{2}{l}{ Social treatment $(\overline{\mathrm{x}} \pm \mathrm{SE})$} \\
\cline { 2 - 3 } Behavioural measure & Winner & Loser \\
\hline No. entries to either retreat-site & $24.2 \pm 1.6$ & $32.4 \pm 4.0$ \\
No. entries to opponent's retreat-site & $12.5 \pm 1.0$ & $16.6 \pm 3.0$ \\
Time spent in opponent's side of tub (h) & $5.1 \pm 0.8$ & $3.7 \pm 0.7$ \\
Time spent active (min) & $116.0 \pm 10.5$ & $216.9 \pm 43.1$ \\
Time spent mobile (min) & $74.1 \pm 9.8$ & $129.2 \pm 19.0$ \\
\hline
\end{tabular}

Moreover, losers spent more time being active and more time being mobile during trials than did winners (ANOva: $\mathrm{df}=1,28, \mathrm{~F}>6.6, \mathrm{p}<0.012$; Table 1).

\section{Discussion}

Velvet geckos can detect and identify integumentary chemical cues deposited by male conspecific lizards. This is evident from an increased tongue-flick rate and the investigation of scented tiles for prolonged periods of time. These responses are qualitatively highly similar to those exhibited by other species of reptiles in analogous experimental conditions (e.g., Cooper \& Vitt 1985; Cooper 1996; Aragon et al. 2001). Moreover, they differ significantly from those displayed toward chemical cues from a male heterospecific lizard that occupies the same microhabitats as velvet geckos.

When offered a choice between retreat-sites labelled with chemicals from an unknown male vs. the opponent from a recent contest, geckos that won their previous fight selected retreat-sites at random. In contrast, under the same conditions, geckos that lost their previous fight preferred retreat-sites scented with an unknown male conspecific over those scented with the winning opponent. During these experiments losers were significantly more likely to actively explore the test arena than were winners, and losers spent more time near the retreat-site of the unknown male than did winners. These results suggest that recent physical social encounters can affect the way that animals respond to subsequent presentations of chemical cues from conspecifics. They further demonstrate that such shifts in response to chemical cues can affect the microhabitat selection in animals.

These outcomes are unlikely to be a spurious result of our protocols. Our retreat-site selection experiment relied on creating focal animals that were distinct winners or losers in previous contests. Contests are most likely to escalate in physical interactions when opponents are evenly matched with respect to ability and motivation to fight (Maynard 
Smith 1982; Stamps \& Krishnan 1994a; Zucker \& Murray 1996). Recent studies demonstrate that animals can assess the body sizes and condition of conspecifics based on chemical cues (Martin \& Lopez 2001; Shine et al. 2003). Therefore, in all trials we matched adult males evenly for (i) body size, (ii) ownership of the limiting resource, and (iii) previous social experience. Importantly, we also controlled for differences in the length and mass of the 'unknown' and 'contestant' lizards used as chemical donors.

Several aspects of the biology of velvet geckos may drive the evolution of using chemoreception to discern among retreat-sites occupied by different males. First, because geckos are nocturnally active, animals may be physically present near defence sites but difficult to identify because of poor lighting (Perret 1992; Schlesinger \& Shine 1994b; Radhakrishna \& Singh 2002). Second, because geckos utilise tight-fitting crevices as retreat-sites, animals may be physically present within defence sites but concealed (Cooper et al. 1996; Downes \& Shine 1998a; Briscoe et al. 2002; White et al. 2002). Third, geckos may be physically absent from defence sites because they range widely from these areas (Cooper et al. 1996; Briscoe et al. 2002; White et al. 2002). The effectiveness of chemical cues for mediating social behaviour is also likely to be linked to rates of fidelity to defence sites (Webb \& Shine 1992; Downes \& Shine 1998a). Field data suggests that geckos are highly loyal to particular outcrops and within these areas move among the same few retreat-sites according to the prevailing weather conditions (Kondo \& Downes, unpubl. data).

The differential selection of chemically labelled retreat-sites by winners and losers is likely to reflect the outcomes of actual physical encounters among males. However, our experiments are not able to distinguish among the mechanism driving the selection of particular retreat-sites. There are at least three explanations for our results that are not mutually exclusive.

First, individual adult male geckos may have different chemical signatures that are stable among a range of situations. In the context of our experiments, this would mean that geckos could identify the chemical cues of opponents as being from a conspecific that it recently met in a contest.

Secondly, individual adult male geckos may have different chemical signatures that vary according to contest outcomes. In the context of our experiments, this would mean that geckos could identify the chemical cues of opponents as being from a conspecific that recently won or lost any contest rather than being from a specific individual that it recently met in a contest. For instance, the act of winning a contest may induce a temporary shift in the production of chemical cues by geckos. In many species animals that win contests with conspecifics undergo shifts in hormone levels and these effects can last for several weeks (Hannes et al. 1984; Frye et al. 2002). In turn, hormones may play a central role in mediating the production of chemical cues (Alberts et al. 1992; Leypold et al. 2002).

Third, individuals of different social standing within the population may have different chemical signatures (Aragon et al. 2000; Carroll 2000). In the context of our experiment, this would mean that geckos could identify the chemical cues of opponents as being from a dominant or subordinate individual rather than being from a specific individual that it recently met in a contest.

Our results predict that (i) geckos which lost previous physical contests may be more likely to win subsequent physical contests against an unknown male compared with an opponent that has previously defeated them and/or has previously won any recent contest and/or is a dominant individual, and (ii) geckos that won previous physical contests may be equally likely to win subsequent contests against an unknown male compared with an opponent that it previously defeated and/or has previously lost any recent contest and/or is a subordinate individual. After the retreat-site selection experiments, we did not stage encounters between focal males and unknown males. However, as part of another study, we staged contests between focal males and their previous opponent. Winner males had an almost $100 \%$ chance of winning subsequent trials, whereas loser males had an almost $0 \%$ chance of winning subsequent trials (J. Kondo, unpubl. data). Therefore, velvet geckos may operate under a system whereby previous contest outcomes affect the subsequent behaviour of loser males but not winner males (Chase et al. 1994).

The present study concerned social behaviour but its findings may extend to other ecological situations in which chemoreception plays a major role, e.g. predation and foraging (Bronmark \& Miner 1992; Jedrzejewska et al. 1993; Schwenk 1995). The existence of intraindividual behavioural syndromes (Sih et al. 2003) indicates that recent experience in one ecological context may also influence the responses of animals to chemical information acquired from another ecological context (Bauwens \& Thoen 1981; Downes \& Bauwens 2002). We therefore recommend that experiments on chemoreception should control for experience in behaviour that may relate 
to information conveyed by the chemicals used in bioassays (Downes \& Bauwens 2002).

\section{Acknowledgements}

D. Couvee, R. Pedroza and S. Way provided valuable field assistance. We thank P. Backwell, P. Cooper, R. Magrath, S. Matchett and the Keogh lab for laboratory assistance and/or helpful discussions. We appreciate the comments of two anonymous reviewers and the Associate Editor of this paper, Dr Jutta Schneider. This project was approved by the Australian National University Ethics and Experimentation Committee, and conducted under NPWS Permit A3033. An Australian Research Council Grant and Australian National University Faculties Research Grant (both to SD) funded the research.

\section{Literature Cited}

Alberts, A. C., Pratt, N. C. \& Phillips, J. A. 1992: Seasonal productivity of lizard femoral glands: relationship to social dominance and androgen levels. Physiol. Behav. 51, 729-733.

Aragon, P., Lopez, P. \& Martin, J. 2000: Size-dependent chemosensory responses to familiar and unfamiliar conspecific faecal pellets by the Iberian rock lizard, Lacerta monticola. Ethology 106, 1115-1128.

Aragon, P., Lopez, P. \& Martin, J. 2001: Discrimination of femoral gland secretions from familiar and unfamiliar conspecifics by male Iberian rock lizards, Lacerta monticola. J. Herpetol. 35, 346-350.

Aragon, P., Lopez, P. \& Martin, J. 2003: Differential avoidance responses to chemical cues from familiar and unfamiliar conspecifics by male Iberian rock lizards (Lacerta monticola). J. Herpetol. 37, 583-585.

Bauwens, D. \& Thoen, C. 1981: Escape tactics and vulnerability to predation associated with reproduction in the lizard Lacerta vivipara. J. Anim. Ecol. 50, 733-743.

Briscoe, B. K., Lewis, M. A. \& Parrish, S. E. 2002: Home range formation in wolves due to scent marking. Bull. Math. Biol. 64, 261-284.

Bronmark, C. \& Miner, J. G. 1992: Predator-induced phenotypical change in body morphology in crucian carp. Science 258, 1348-1351.

Bull, C. M., Griffin, C. L. \& Johnston, G. R. 1999: Olfactory discrimination in scat-piling lizards. Behav. Ecol. 10, 136-140.

Carroll, J. F. 2000: Interdigital gland substances of whitetailed deer and the response of host-seeking ticks (Acari: Ixodidae). J. Med. Entomol. 38, 114-117. Chase, I. D., Bartolomeo, C. \& Dugatkin, L. A. 1994: Aggressive interactions and inter-contest interval: how long do winners keep winning? Anim. Behav. 48, 393-400.

Cogger, H. G. 2000: Reptiles and Amphibians of Australia, 6th edn. New Holland Publishers, Australia, Sydney.

Cooper, W. E. 1996: Chemosensory recognition of familiar and unfamiliar conspecifics by the scincid lizard Eumeces laticeps. Ethology 102, 454-464.

Cooper, W. E. \& Perez-Mellado, V. 2002: Pheromonal discriminations of sex, reproductive condition, and species by the lacertid lizard Podarcis hispanica. J. Exper. Zool. 292, 523-527.

Cooper, W. E. \& Vitt, L. J. 1985: Responses of the skinks, Eumece fasciatus and E. laticeps, to airborne conspecific odors: further appraisal. J. Herpetol. 19, 481-486.

Cooper, W. E., VanWyk, J. H. \& Mouton, P. L. N. 1996: Pheromonal detection and sex discrimination of conspecific substrate deposits by the rock-dwelling cordylid lizard Cordylus cordylus. Copeia 1996, 839-845.

D'Ettorre, P., Heinze, E., Schulz, C., Francke, W. \& Ayasse, M. 2004: Does she smell like a queen? Chemoreception of a cuticular hydrocarbon signal in the ant Pachycondyla inversa. J. Exper. Biol. 207, 1085-1091.

Downes, S. J. \& Adams, M. 2001: Geographic variation in antisnake tactics: the evolution of scent-mediated behavior in a lizard. Evolution 55, 605-615.

Downes, S. J. \& Bauwens, D. 2002: The outcome of first encounters affects ensuing social relations within dyads of two species of lacertid lizards. Behav. Ecol. 15, 938-945.

Downes, S. \& Shine, R. 1998a: Heat, safety or solitude? Using habitat selection experiments to identify a lizard's priorities. Anim. Behav. 55, 1387-1396.

Downes, S. \& Shine, R. 1998b: Sedentary snakes and gullible geckos: predator-prey coevolution in nocturnal rock-dwelling reptiles. Anim. Behav. 55, 1373-1385.

Frye, C. A., Rhodes, M. E., Walf, A. \& Harney, J. P. 2002: Testosterone enhances aggression of wild-type mice but not those deficient in type I 5 alpha-reductase. Brain Res. 948, 165-170.

Hannes, R. P., Franck, D. \& Liemann, F. 1984: Effects of rank-order fights on whole-body and blood concentrations of androgens and corticosteroids in the male swordtail (Xiphophorus helleri). J. Comp. Ethol. 65, 53-65.

Hurst, J. L., Gray, S. J., Davey, P., Young, D., Corbishley, J. \& Dawson, C. 1997: Social interaction alters attraction to competitor's odour in the moose Mus spretus Lataste. Anim. Behav. 54, 941-953.

Jedrzejewska, J., Rychlik, L. \& Jedrzejewska, B. 1993: Responses of bank voles to odours of seven species of predators: experimental data and their relevance to natural predator-vole relationships. Oikos $6 \mathbf{8 8}$, $251-257$.

Kondo, J. \& Downes, S. 2004: Using visible implant elastomer to individually mark geckos. Herpetofauna 34, $19-22$. 
Lena, J. P., De Fraipont, M. \& Clobert, J. 2000: Affinity towards maternal odour and offspring dispersal in the common lizard. Ecol. Lett. 3, 300-308.

Leypold, B. G., Yu, C. R., Leinders-Zufall, T., Kim, M. K., Zufall, F. \& Axel, R. 2002: Altered sexual and social behaviours in trp2 mutant mice. Proc. Natl Acad. Sci. USA 99, 6376-6381.

Lopez, P., Aragon, P. \& Martin, J. 2003: Responses of female lizards, Lacerta monticola, to males' chemical cues reflect their mating preference for older males. Behav. Ecol. Sociobiol. 55, 73-79.

Luque-Larena, J. J., Lopez, P. \& Gosalbez, J. 2001: Scent matching modulates space use and agonistic behaviour between male snow voles, Chionomys nivalis. Anim. Behav. 62, 1089-1095.

Martin, J. \& Lopez, P. 2001: Repeated predatory attacks and multiple decisions to come out from a refuge in an alpine lizard. Behav. Ecol. 12, 386-389.

Maynard Smith, J. 1982: Evolution and the Theory of Games. Cambridge Univ. Press, New York.

Olsson, M. 1994: Nuptial coloration in the sand lizard, Lacerta agilis: an intra-sexually selected cue to fighting ability. Anim. Behav. 48, 607-613.

Orviel, J., Errard, C. \& Dejean, A. 1997: Ant gardens: interspecific recognition in parabiotic ant species. Behav. Ecol. Sociobiol. 40, 87-93.

Perret, M. 1992: Environmental and social determinants of sexual function in the male lesser mouse lemur (Microcebus murinus). Folia Promatol. 59, 1-25.

Qualls, C. P. \& Jaeger, R. G. 1991: Dear enemy recognition in Anolis carolinenis. J. Herpetol. 25, 361-363.

Radhakrishna, S. \& Singh, M. 2002: Social behaviour of the slender loris (Loris tardigradus lydekkerianus). Folia Primatol. 73, 181-196.

Sakata, J. T., Gupta, A. J., Chuang, C. \& Crews, D. 2002: Social experience affects territorial and reproductive behaviours in male leopard geckos, Eublepharis macularius. Anim. Behav. 63, 487-493.

Schlesinger, C. A. \& Shine, R. 1994a: Selection of diurnal retreat sites by the nocturnal gekkonid lizard Oedura lesueurii. Herpetology 50, 156-163.

Schlesinger, C. A. \& Shine, R. 1994b: Choosing a rock: perspectives of a bush-rock collector and a saxicolous lizard. Biol. Conserv. 67, 49-56.

Schneider, R. A. Z., Schneider, R. W. S. \& Moore, P. A. 1999: Recognition of dominance status by chemorecep- tion in the red swamp crayfish, Procambarus clarkii. J. Chem. Ecol. 25, 781-794.

Schwenk, K. 1995: Of tongues and noses: chemoreception in lizards and snakes. Tree 10, 7-12.

Shine, R., Phillips, B., Waye, H., Lemaster, M. \& Mason, R. T. 2003: Chemosensory cues allow courting male garter snakes to assess body length and body condition of potential mates. Behav. Ecol. Sociobiol. 54, 162-166.

Sih, A., Kats, L. B. \& Maurer, E. F. 2003: Behavioural correlations across situations and the evolution of antipredator behaviour in a sunfish-salamander system. Anim. Behav. 65, 29-44.

Stamps, J. A. \& Krishnan, V. V. 1994a: Territory acquisition in lizards II: establishing social and spatial relationships. Anim. Behav. 47, 1387-1400.

Takahashi, S. \& Gassa, A. 1995: Roles of cuticular hydrocarbons in intra- and inter-specific recognition of two Rhinotermitidae species. J. Chem. Ecol. 21, 1837-1845.

Temeles, E. J. 1994: The role of neighbors in territorial systems: when are they dear enemies. Anim. Behav. 47, 339-350.

Webb, J. K. \& Shine, R. 1992: To find an ant: trail-following in Australian blindsnakes (Typhlopidae). Anim. Behav. 43, 941-948.

Webb, J. K. \& Shine, R. 2000: Paving the way for habitat restoration: can artificial rocks restore degraded habitats of endangered reptiles? Biol. Conserv. 92, 93-99.

White, A. M., Swaisgood, R. R. \& Zang, H. M. 2002: The highs and lows of chemical communication in giant pandas (Ailuropoda melanoleuca): effect of scent deposition height on signal discrimination. Behav. Ecol. Sociobiol. 51, 519-529.

Whiting, M. J. 1999: When to be neighbourly: differential agonistic responses in the lizard Platysaurus broadleyi. Behav. Ecol. Sociobiol. 46, 210-214.

Wunderle, J. M. J. 1978: Differential response of territorial yellow-throats to the songs of neighbors and non-neighbors. Auk 95, 389-395.

Ydenberg, R. C., Giraldeau, L. A. \& Falls, J. B. 1988: Neighbours, strangers, and the asymmetric war of attrition. Anim. Behav. 36, 343-347.

Zucker, N. \& Murray, L. 1996: Determinants of dominance in the tree lizard Urosaurus ornatus: the relative importance of mass, previous experience and coloration. Ethology 102, 812-825. 